\title{
Automatic Quantitative Analysis of the Electromyogram in Partially Denervated Distal Muscles: Comparison with Motor Unit Counting
}

\author{
A.J.McCOMAS AND R.E.P.SICA
}

SUMMARY: Using the ANOPS-101 minicomputer, an automatic analysis of muscle action potentials (MAP) was performed on a total of 53 extensor digitorum brevis $(E D B)$ and abductor pollicis brevis (APB) muscles in patients with other evidence of denervation. The results were compared with observations made on 27 control subjects and they were also matched against estimates of functioning motor units made

RESUME: Nous avons fait une analyse automatique des potentiels d'actions musculaires (MAP), à l'aide du miniordinateur ANOPS-101, et ceci sur un total de 53 muscles extenseurs courts des doigts (EDB) et adducteurs courts du pouce $(A P B)$ chez des patients ayant d'autre $\dot{e}-$ vidence de dénervation. Ces résultats sont comparés aux observations faites chez 27 sujets contrôles et également aux estimés

From the Medical Research Council Group in Developmental Neurobiology, McMaster University. Hamilton. Ontario. Canada.

Reprint requests to: Dr. Alan J. McComas, Department of Neurology, Room 4U7, McMaster University Medical Centre, 1200 Main Street West, Hamilton. Ontario, Canada L8S 419. by the incremental stimulating technique of McComas et al (1971). Although the incidence of abnormal MAP parameters was relatively low in both muscles, it was possible to improve the diagnostic yield by combining the results for individual muscles. The relative merits and disadvantages of motor unit counting and automatic MAP analysis are discussed.

du nombre d'unités motrices fonctionnelles selon la méthode de McComas (197I). Malgré que l'incidence de MAP anormaux fut relativement basse pour les deux muscles, il fut possible d'améliorer le rendement diagnostic en combinant les résultats pour les muscles individuels. On discute ainsi les mérites respectifs et les désavan. tages des comptes d'unités motrices versus l'analyse automatique des MAP.

\section{INTRODUCTION}

In a companion paper (Sica, McComas and Ferreira, 1978), the results have been described of a quantitative analysis of the EMG using a fixedprogramme mini-computer (ANOPS101; Technical University of Warsaw). In that study, which was confined to two proximal muscles of the limbs, the biceps brachii and vastus medialis, it was found that the analytical system was successful in detecting abnormalities in myopathic disorders, but was less satisfactory for the diagnosis of denervation. The yield of abnormal results in patients was significantly higher in the biceps brachii than in the vastus medialis, largely because the control observations used for comparison had a smaller scatter in the biceps. Although there have been other recent reports of automated examinations of the EMG (FuglsangFrederiksen, Scheel and Buchthal,
1976, 1977; Hayward and Willison, 1977; Kopec and HausmanowaPetrusewicz, 1976), these, like that of Sica et al (1978), have been confined to relatively large muscles in the limbs. In the present investigation we have extended this type of study to intrinsic muscles of the hand and foot by investigating the abductor pollicis brevis (APB) and extensor digitorum brevis (EDB), respectively. A feature of this study has been a comparison of the results in patients known to have neuropathic lesions with those obtained by the method of motor unit counting (McComas et al, 1971; Sica et al, 1974).

\section{METHODS}

Subjects

\section{Controls:}

Sixteen males and 11 female subjects, free of neurological and other disease, served as controls; their ages ranged from 20 to 58 years. The subjects volunteered for the study after full explanations had been given; financial rewards were provided. The study carried the approval of the Ethics Committee of the Research Advisory Group at McMaster University.

\section{Patients:}

Twenty male and 17 female patients, aged between 22 and 71 , were examined. Six patients had motoneuron disease, 8 had carpal tunnel syndromes, 5 had peripheral neuropathies, 15 had evidence of cervical and/or lumbosacral root compression; 3 subjects who were in good health but who were over the age of 60 were also studied, since they would have been susceptible to the neuropathic changes which accompany ageing (Campbell et al, 1973; Sica et al, 1974). 
In the six patients with motoneuron disease, the clinical findings were typical of that condition and the disease was sufficiently far advanced to have produced moderately severe wasting and weakness of the distal muscles of the limbs. In the eight patients with carpal tunnel syndromes, the clinical diagnosis had been confirmed by the finding of slowed conduction in cutaneous sensory fibers across the wrist; only in two patients was there definite muscle atrophy. The patients considered to have spinal nerve root involvement had the clinical features characteristic of this type of disorder, together with radiological evidence suggestive of disc protrusion or of osteophyte formation; the diagnosis was supported by EMG examination. None of the APB muscles and two of the EDB muscles in the group of patients with suspected root lesions were atrophied.

\section{ELECTROMYOGRAPHY}

The subjects lay supine upon a couch; the ambient temperature was 22 - $24^{\circ} \mathrm{C}$. For the examination of APB, the thumb was abducted in a vertical direction with the dorsum of the hand resting on the couch. During both minimal and maximal isometric contraction, the observer applied resistance to the thumb when the latter was approximately $45^{\circ}$ to the horizontal. For EDB, the ankle was in its resting position and the observer provided resistance to the great toe during attempted extension.

The extensor digitorum brevis (EDB) and abductor pollicis brevis (APB) muscles were examined with a coaxial needle electrode (Disa type 9013L0501). Two penetrations were made into each muscle and recordings were made at two depths, approximately $0.5 \mathrm{~cm}$ apart. The position of the electrode tip was only adjusted if sharply rising potentials did not appear during weak voluntary contraction. The muscle action potentials underwent pre-amplification, with attenuation of frequencies beyond $3 \mathrm{~Hz}$ and $10 \mathrm{kHz}$, and they were then displayed on a Hewlett-Packard Model $141 \mathrm{~B}$ oscilloscope and also entered into an ANOPS-101 computer; the latter was connected to a desk-top calculator and X-Y plotter (Hewlett-Packard models $9810 \mathrm{~A}$ and $9862 \mathrm{~A}$ ).

\section{DETERMINATION OF MUSCLE ACTION POTENTIAL (MAP) PARAMETERS}

\section{Durations and Phases.}

These estimations were performed simultaneously during weak voluntary contraction. The pre-amplifier gain was set so that only potentials greater than $100 \mu \mathrm{V}$ (decision level) were selected by the computer for analysis; measurements of duration were made to $20 \mu \mathrm{V}$ of the baseline (detection level). The complexity of the same potentials was measured, a reversal of polarity in excess of $40 \mu \mathrm{N}$ being accepted as an additional potential phase. Two hundred and fifty six potentials were analysed at each of the four recording sites in each muscle.

\section{Intervals and Amplitudes.}

With the tip of the recording electrode in the last of the four sites to be studied (above), the subject was asked to make four maximal voluntary contractions; these were separated from each other by approximately 15

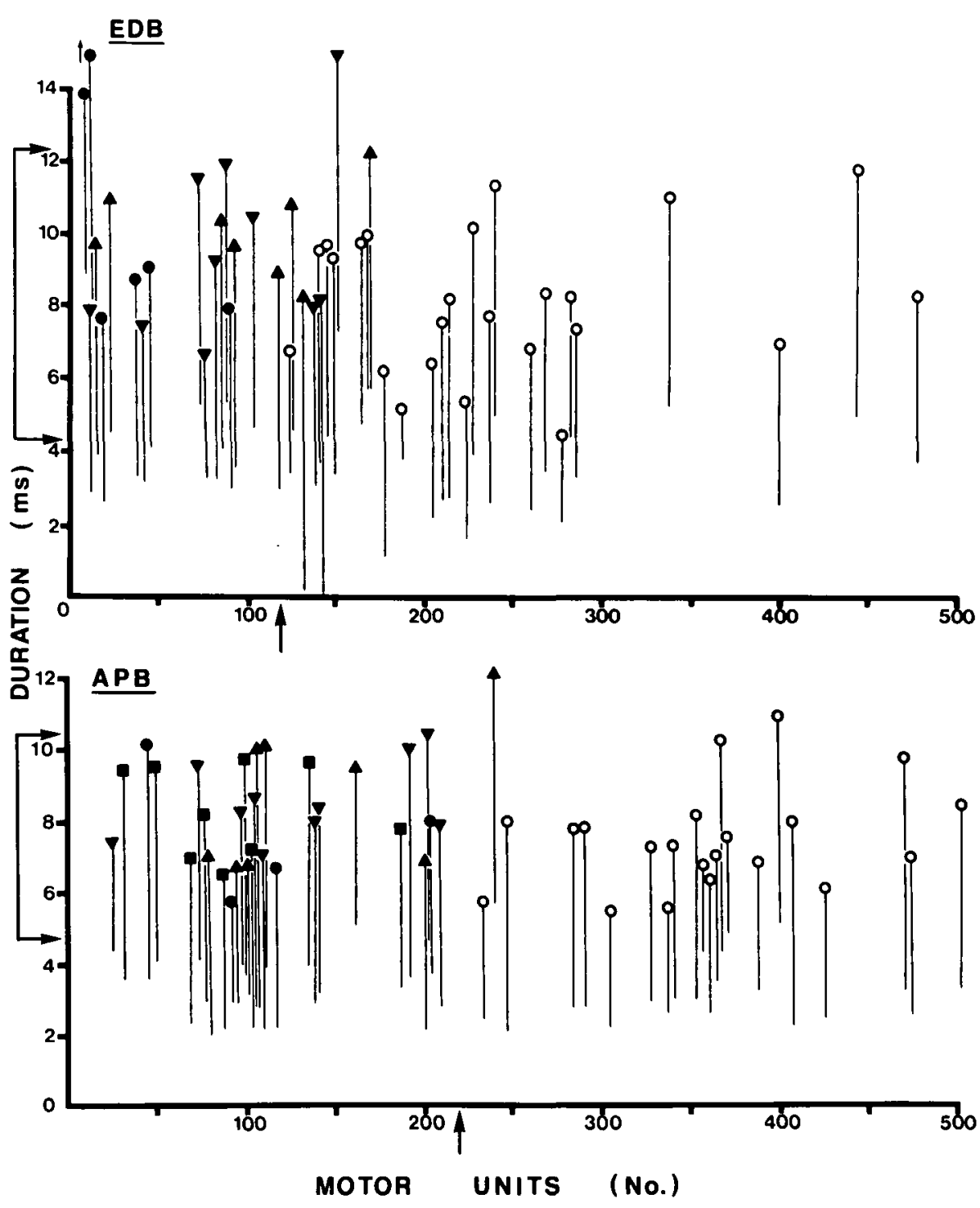

Figure 1 - Mean M-AP durations (-SD) for EDB and APB muscles of controls $(O)$ and patients with motoneuron disease $(\bullet)$, carpal tunnel syndromes $(\boldsymbol{\square})$, neuropathy or ageing $(\boldsymbol{\nabla})$, and root compression $(\boldsymbol{\Delta})$. Values are plotted against estimates of numbers of functioning motor units in EDB and median-innervated thenar muscles. Arrow on abscissa indicates lower limit of control range for number of motor units; linked arrows on ordinate denote mean control MAP duration $\pm 2 \mathrm{SD}$. 
seconds. The density of the interference pattern was found by measuring the time intervals between successive peaks of negative potentials greater than 50 $\mu \mathrm{V}$. It should be noted that the mean interval will be twice that calculated by the method of turns analysis pioneered by Willison (1964) and described by Hayward (1977), Hayward and Willison (1977) and FuglsangFrederiksen et al, (1976, 1977). The mean amplitudes of positive and negative potentials greater than $50 \mu \mathrm{V}$ were also measured. For most subjects, additional runs were made using 100 ${ }_{\mu} \mathrm{V}$ as the critical level for acceptance.

\section{MOTOR UNIT COUNTING}

The numbers of functioning motor units were estimated in the same muscles used for quantitative EMG analysis. The techniques used were those described by McComas et al, (1971) for EDB and by Sica et al, (1974) for median-innervated thenar muscles. The principle of the method is to record, with surface electrodes, the muscle action potentials (MAPs) evoked by weak graded stimulation of the appropriate motor nerve. On the assumption that each increment in the response reflects the excitation of an additional motor unit, the number of
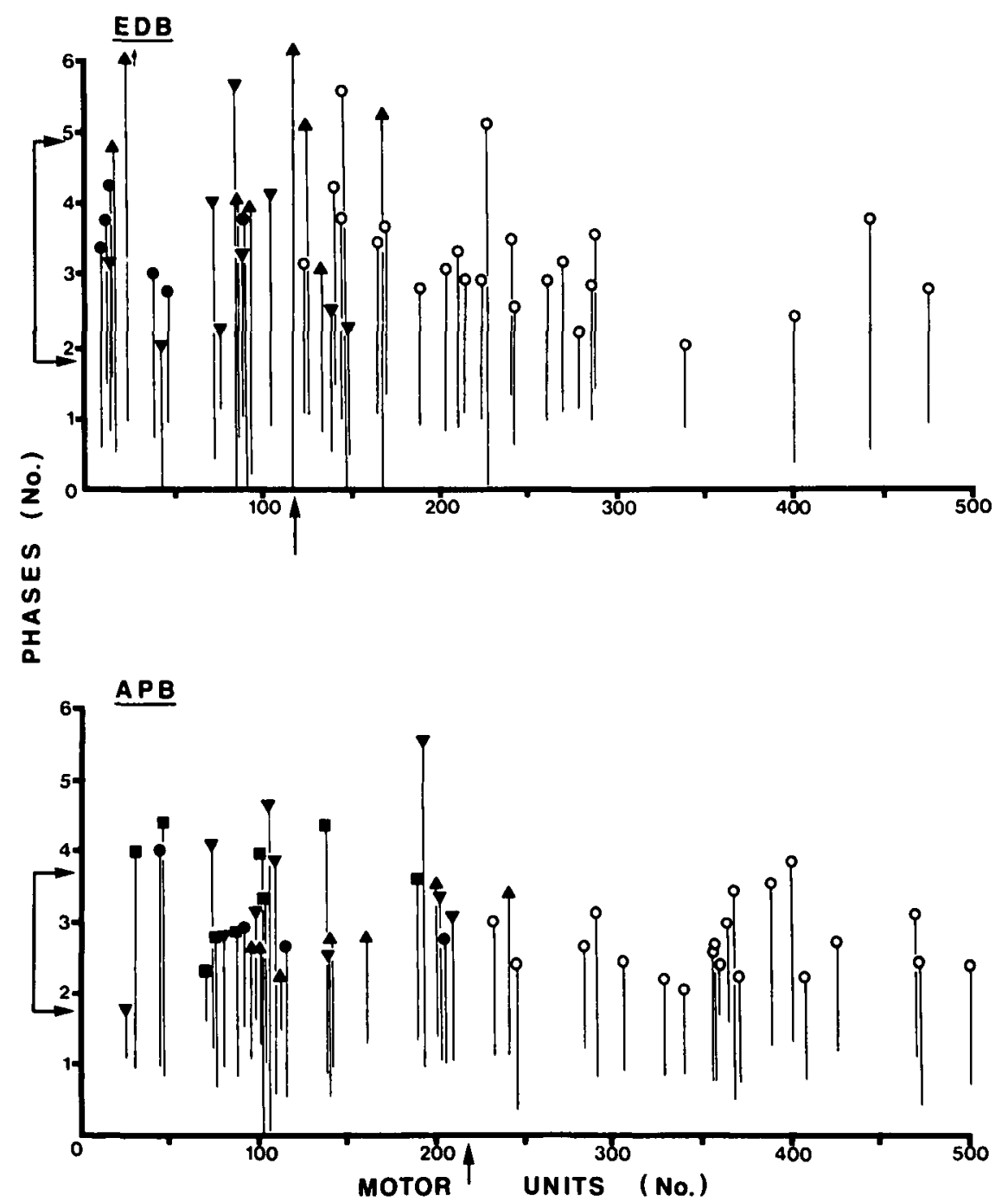

Figure 2 - Mean numbers of MAP phases (-SD) for EDB and APB muscles of controls and patients with denervating disorders (symbols as in Fig. 1). Values are plotted aginst estimates of numbers of functioning motor units in EDB and median-innervated thenar muscles. Arrow on abscissa indicates lower limit of control range for number of motor units; linked arrows on ordinate signify mean number of MAP phases in controls \pm 2 SD.

functioning units can be roughly estimated by comparing the amplitude of the maximum evoked muscle response with the mean amplitude of the sample of incremental potentials.

\section{RESULTS \\ Control Subjects}

In Fig. 1, it can be seen that in all the control subjects the numbers of functioning motor units in the EDB and thenar muscles lay within the corresponding ranges determined previously for control subjects (McComas et al, 1971; Sica et al, 1974). The mean values of $243 \pm 75$ EDB units and $362 \pm 70$ thenar units may be compared with recently reported control means of 210 and 342 units, respectively (McComas, 1977). The coaxial needle study yielded mean values for four parameters, namely the durations and numbers of phases of individual MAPs and the densities and amplitudes of potentials comprising maximal interference patterns; the mean values are shown in Tables 1 and 2. The mean number of phases was observed to be significantly higher in EDB than in APB; only small differences, not of statistical significance, were found in comparing the other parameters between the two muscles. With the exception of the increased polyphasicity of EDB, the present values were close to the mean results determined for the vastus medialis and brachial biceps muscles by Sica et al (1978) in the same control subjects.

\section{EDB MUSCLES IN PATIENTS}

The results from individual patients with partial denervation were compared with those of controls; patient values were regarded as abnormal if they differed by more than two standard deviations from the corresponding control mean. Of the 23 EDB muscles, 14 had one or more abnormal parameters (Table 3); in 3 of these muscles two values were abnormal. The least abnormal measurement was that of potential amplitude, as determined from the interference pattern; in only one instance did this fall outside the normal range.

When the results from the patients were pooled, the mean values differed significantly from those of controls in 
relation to the durations of the potentials and the densities of the interference patterns (Table 1). The latter parameter also differed significantly from the control mean when the mean values for the two groups of patients with motoneuron disease and with peripheral neuropathy, respectively, were considered separately. Significar:t discrepancies from normal also emerged for the mean durations and numbers of phases of the patients with lumbosacral root lesions. For the 6 patients with motoneuron disease, the mean interval was the only parameter to differ significantly from the control mean; in three of the patients, two of whom had advanced disease and severe losses of functioning motor units, all four parameters were within the $95 \%$ confidence limits for controls.

In Figs. 1 to 4 the results for individual patients have been plotted as functions of the respective motor unit counts. No correlation could be found between the reduction in motor unit count and the degree of abnormality in any of the four MAP parameters. However, it is interesting that of the four patients with normal motor unit counts, but in whom lumbosacral root pathology was suspected, three had EDB muscles with one or more EMG parameters which exceeded the corresponding normal range.

\section{APB MUSCLES IN PATIENTS}

The results in partially denervated APB muscles were also compared with corresponding control values. Using $95 \%$ confidence limits, 15 of the 30 muscles appeared abnormal but in only one of these were two parameters affected. The measurements of MAP complexity (number of phases) showed the highest incidence of deviations from normal; the other three parameters were much less frequently involved (Table 3).

The analysis of the pooled data (Table 2) confirmed that the number of phases was the most abnormal of the four parameters since it alone provided a mean which differed significantly from the respective control value. A significant increase in polyphasicity was also found for the subgroup of 8 patients with carpal tunnel syndromes.

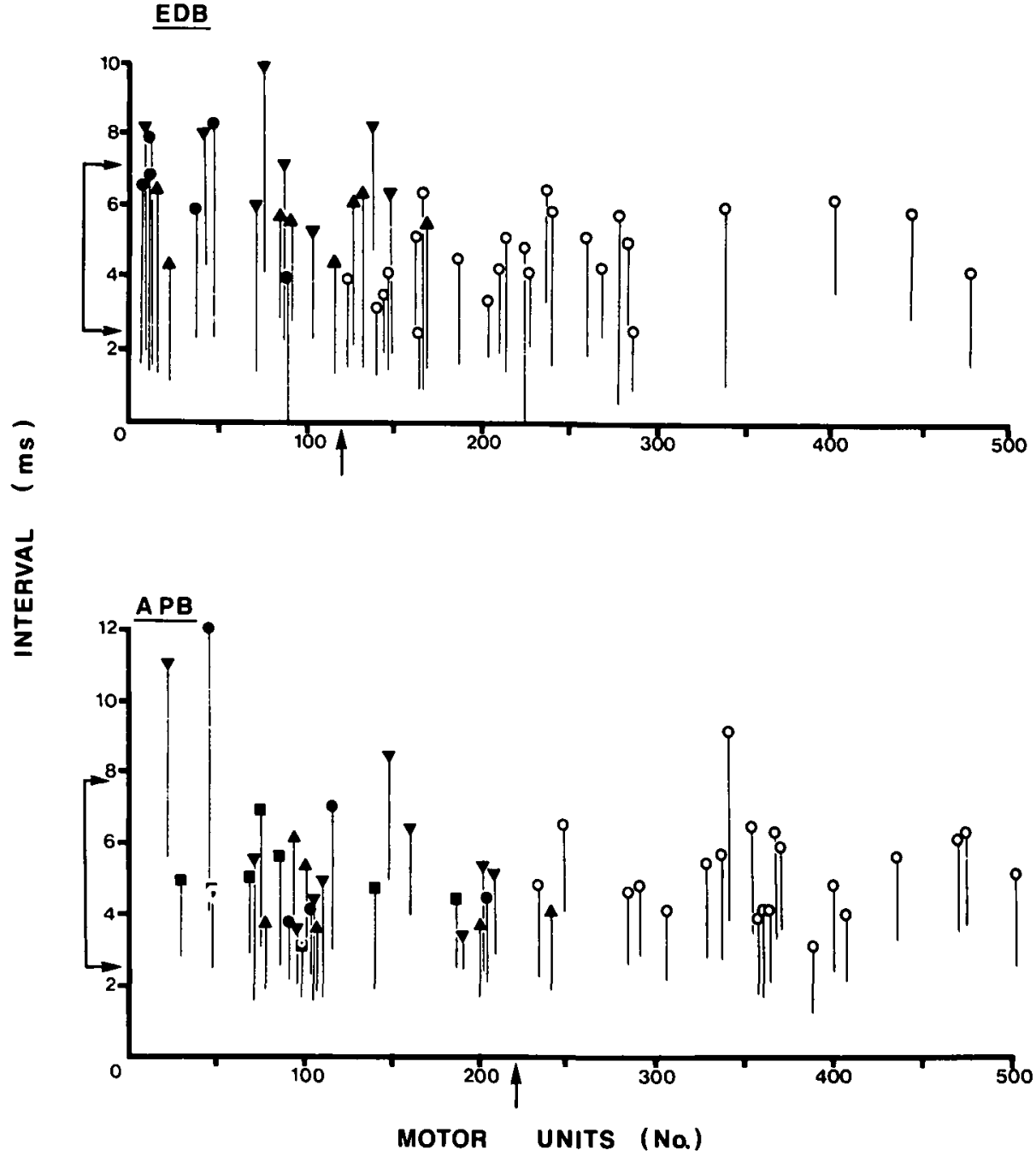

Figure 3 - Mean intervals (-SD) between successive negative potentials of interference pattern during maximum effort. Symbols for patients and controls as in Fig. 1. Values are shown against numbers of functioning motor units in EDB and median-innervated thenar muscles. Arrow on abscissa indicates lower limit of control range for number of motor units; linked arrows on ordinate denote mean potential interval in controls \pm 2 SD.

\begin{tabular}{lcccc}
\hline & $\begin{array}{c}\text { DURATION } \\
(\mathrm{ms})\end{array}$ & $\begin{array}{c}\text { PHASES } \\
(\mathrm{no})\end{array}$ & $\begin{array}{c}\text { INTERVAL } \\
(\mathrm{ms})\end{array}$ & $\begin{array}{c}\text { AMPLITUDE } \\
(\mathrm{mV})\end{array}$ \\
\hline CONTROL (24) & $8.23 \pm 1.99$ & $3.35 \pm 0.78$ & $4.75 \pm 1.16$ & $0.87 \pm 0.14$ \\
AGEING (3) & $12.15 \pm 2.86$ & $3.75 \pm 1.72$ & $6.84 \pm 0.57$ & $0.93 \pm 0.03$ \\
L5 ROOT LESION (9) & $10.28 \pm 1.41$ & $5.22 \pm 1.97$ & $5.69 \pm 0.91$ & $0.85 \pm 0.17$ \\
& $(<.05)$ & $(<.01)$ & & \\
PERIPHERAL & $8.69 \pm 1.91$ & $3.06 \pm 0.90$ & $7.50 \pm 1.53$ & $0.77 \pm 0.17$ \\
NEUROPATHY (5) & $11.06 \pm 4.36$ & $3.53 \pm 0.55$ & $\begin{array}{c}6.62 \pm 1.60 \\
(<.025)\end{array}$ & $0.95 \pm 0.23$ \\
MOTONEURON & $10.32 \pm 2.80$ & $4.02 \pm 1.62$ & $6.54 \pm 1.42$ & $0.86 \pm 0.19$ \\
DISEASE (6) & $(<.01)$ & & $(<.001)$ & \\
ALL PATIENTS (23) & & & & \\
& & & &
\end{tabular}

Table 1. Extensor digitorum brevis (EDB). Mean MAP parameters ( \pm SD) for controls and patients with various denervating disorders. Significant differences between patient and control means are indicated. Numbers of patients examined are given in parentheses after each category in Table. 

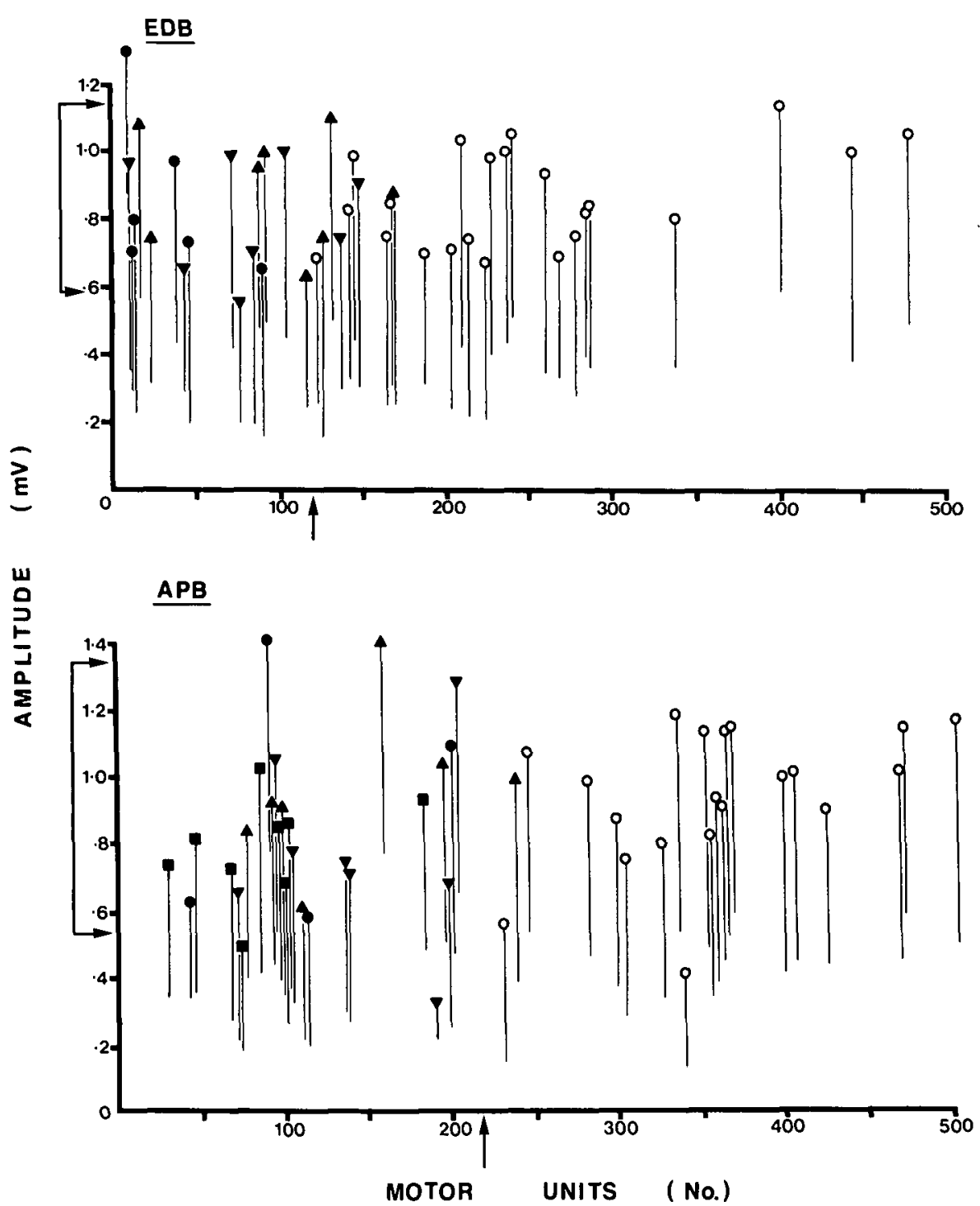

Figure 4- Mean amplitude of potentials (-SD) comprising interference pattern during maximum effort. Symbols for patients and controls as in Fig. 1. Values are plotted against numbers of functioning motor units in EDB and median-innervated thenar muscles. Arrow on abscissa indicates lower limit of control range for number of motor units; linked arrows on ordinate show mean potential amplitude in controls $\pm 2 \mathrm{SD}$.

\begin{tabular}{lcccc}
\hline & $\begin{array}{c}\text { DURATION } \\
(\mathrm{ms})\end{array}$ & $\begin{array}{c}\text { PHASES } \\
(\mathrm{no})\end{array}$ & $\begin{array}{c}\text { INTERVAL } \\
(\mathrm{ms})\end{array}$ & $\begin{array}{c}\text { AMPLITUDE } \\
(\mathrm{mV})\end{array}$ \\
\hline CONTROL (21) & $7.58 \pm 1.44$ & $2.74 \pm 0.48$ & $5.16 \pm 1.31$ & $0.94 \pm 0.20$ \\
AGEING (3) & $9.71 \pm 1.13$ & $4.04 \pm 1.33$ & $4.02 \pm 1.04$ & $0.80 \pm 0.41$ \\
CARPAL TUNNEL (8) & $8.19 \pm 1.21$ & $3.59 \pm 0.70^{*}$ & $5.19 \pm 0.97$ & $0.76 \pm 0.19$ \\
CERVICAL ROOT (10) & $8.50 \pm 1.69$ & $3.04 \pm 0.61$ & $4.45 \pm 1.04$ & $0.86 \pm 0.21$ \\
PERIPHERAL & $8.22 \pm 0.88$ & $3.35 \pm 1.07$ & $6.17 \pm 2.83$ & $0.87 \pm 0.23$ \\
NEUROPATHY (5) & & & & \\
MOTONEURON DISEASE (4) & $7.72 \pm 1.94$ & $3.07 \pm 0.62$ & $7.00 \pm 3.34$ & $1.02 \pm 0.55$ \\
ALL PATIENTS (30) & $8.41 \pm 1.47$ & $3.30 \pm 0.82^{*}$ & $5.24 \pm 2.06$ & $0.85 \pm 0.29$ \\
\hline
\end{tabular}

Table 2. Abductor pollicis brevis (APB). Mean MAP parameters ( \pm SD) for controls and patients with various denervating disorders. Asterisks indicate the only two results which differed significantly from control values $(P=<.02)$. Numbers of patients examined are given in parentheses after each category in Table.
The findings for individual patients were also compared with motor unit counts in the same muscles and the results are shown in Figs. 1 to 4 . As with EDB, it can be seen that there was no correlation between the two types of study, other than the observation that two of the three muscles with the lowest motor unit counts gave the greatest reduction in interference pattern density (Fig. 3).

\section{DISCUSSION}

The EMG activity in APB and EDB muscles has been studied in control subjects and in patients who, on the basis of clinical and laboratory data, were judged likely to have partial denervation of these muscles. The choice of EDB as the most suitable intrinsic muscle of the foot for investigation depended on its accessibility, the ease of detecting any atrophy by inspection, and its extensive use in motor unit counting studies (see also Ballantyne and Hansen, 1974; Brown, 1972). A further advantage of using this muscle is that, in the monkey, it has recently been employed for a comparison of anatomical and physiological estimates of motor unit numbers (Peyronnard and Lamarre, 1977). The choice of EDB could be criticised on the grounds that histological evidence suggestive of chronic denervation has been found in normal subjects (Jennekens, Tomlinson and Walton, 1972). In comparison with the findings in APB, the EDB would have been expected to exhibit increases in MAP duration and also in the intervals and amplitudes of the potentials in the interference pattern, in keeping with the presence of mild denervation. Rather surprisingly, a significant difference between the two muscles could only be shown for the mean number of phases $(\mathrm{P}=.01)$.

When the results in patients were analysed, the incidence of quantitative EMG abnormalities was found to be surprisingly low, amounting to 16 out of 120 measurements for APB and to 20 out of 92 for EDB. All of the 36 abnormalities were of a kind which could have been predicted from conventional EMG theory. Thus MAP durations tended to be longer while the amplitudes were larger; the numbers of 


\section{DURATION PHASES INTERVAL AMPLITUDE ALL PARAMETERS}

\begin{tabular}{llllll}
\hline EDB & 17 & 22 & 30 & 4 & 61 \\
$(23$ muscles $)$ & 7 & 30 & 10 & 10 & 50 \\
$\begin{array}{l}\text { APB } \\
(30 \text { muscles })\end{array}$ & & & & \\
\hline
\end{tabular}

Table 3. Percentage EMG abnormalities in EDB and APB muscles of patients as estimated by $95 \%$ confidence limits for controls (i.e. mean $\pm 2 \mathrm{SD}$ ). The column at the right gives the cumulative incidence of demonstrably abnormal muscles using all four MAP parameters.

phases were increased and the densities of the interference patterns were reduced. When the APB results for all the patients with denervation were pooled, the only parameter to differ significantly from the corresponding control value was the mean number of phases. For EDB, significant differences from normal were found for the mean MAP duration and the mean potential interval in the interference pattern. When the results for each type of denervation were considered, significant changes could be demonstrated in the EDB muscles of those patients with lumbar root lesions, peripheral neuropathies, and motoneuron disease. It was surprising, nevertheless, that 3 of the 6 EDB muscles in the patients with motoneuron disease gave entirely normal results; one of the 3 muscles was estimated to contain only 16 motor units, corresponding to greater than 90 percent denervation. When the APB muscles were considered, only the group of patients with carpal tunnel syndromes yielded a mean MAP parameter which differed significantly from the control value.

Although the number of observations was small, it appeared that the number of phases was the most useful test for denervation in APB; this measurement, together with those of MAP duration and interference pattern interval, was most likely to be abnormal in EDB. In contrast, the mean interference pattern amplitudes were significantly raised in only 4 of the 53 muscles examined. It is relevant that, in comparison with the other 3 MAP parameters, amplitude measurements were of least value in the diagnosis of denervation in partially denervated biceps brachii muscles (Sica et al, 1978).
An important feature of the ANOPS system is that, by measuring 4 parameters from each muscle rather than one, it enables the results to be combined in various ways. If one of the four parameters falls more than two standard deviations beyond the corresponding control mean, there is a $95 \%$ chance that the muscle is abnormal. If, as in the case of five of the 53 muscles examined, two parameters are abnormal; then the likelihood that the muscle itself is abnormal rises to $99.75 \%$. However, there is also a potential danger in combining results. If four parameters are considered for a given muscle and only one of these yields an abnormal result, the likelihood that the muscle is diseased is no longer $95 \%$ but $80 \%$. Conversely, one in every five control subjects would be expected to yield one parameter for which the result exceeded the $95 \%$ confidence limits. In the present study, 14 of the 23 EDB muscles and 15 of the 30 APB muscles had at least one abnormal parameter.

How well do the results of quantitative electromyography and the technique itself compare with motor unit counting? While the reliability of the latter technique is still questioned (see McComas, 1977, for review), there is no doubt that this type of test has an empirical usefulness in the detection of denervation (Brown and Feasby, 1974; Hansen and Ballantyne, 1972; Panayiotopoulos and Scarpalezos, 1975). Animal studies indicate that the results may be accurate in normal muscles and in those with ischaemic lesions; conflicting results have been obtained in partially denervated muscles (Eisen, Karpati, Carpenter and Danon, 1974; Peyronnard and Lamarre, 1977). In relation to automatic EMG analysis, the motor unit counting technique employed in this study occupies approximately the same time but it requires simpler and less expensive apparatus; in addition, it is our experience that patients find electrical stimulation less objectionable than needle insertion. By estimating the number of functioning motor units (and hence motor axons) rather than some aspect of the MAP, the motor unit counting method provides results with biological and practical significance. Against this is the fact that reinnervation of a muscle may not completely reverse the abnormal architectural changes accompanying prior denervation. Thus it is possible that a muscle might regain its full complement of motor units but that abnormal fiber type grouping might persist. Changes of this kind have been postulated to occur in the EDB muscles of normal subjects (Ballantyne and Hansen, 1974; McComas, 1977). In such circumstances, quantitative analysis of MAP parameters might be abnormal, although the number of functioning motor units would be within the normal range. It is possible that this explanation accounts for the finding of 3 EDB muscles with normal motor unit counts and abnormal MAP parameters. It should also be noted that the motor unit counting technique does contain a subjective component and its accuracy in experienced hands is such as to give coefficients of variation in the $10-13$ percent range for APB and EDB (unpublished observations). Further, although the motor unit count was decreased in 49 of 53 muscles studied, it could be argued that this comparatively high incidence had been biased by using the range of control observations for the determination of the normal lower limit rather than two standard deviations below the mean. The latter mode of comparison has been avoided in motor unit counting studies because of the skewed distribution of values about the control mean which is a consequence of the division step in the calculation of motor unit numbers. Even if a value of two standard deviations below the mean was taken as the $95 \%$ confidence limit for the control population, all but one of the 30 thenar muscle groups in the patients would still have yielded low motor unit counts; for EDB, the cor- 
responding figure would have been 16 abnormal muscles out of 23 . These proportions may be compared with an overall incidence of 29 abnormal APB and EDB muscles out of 53 using quantitative EMG. However, it has already been pointed out that although abnormal muscles are more likely to be detected by combining the results for the four parameters, the incidence of false positive results also rises. As a consequence of these considerations and the present findings, we believe that the greatest usefulness of an automatic method of EMG analysis, such as the ANOPS system, is in the study of those muscles for which motor unit counting is not technically feasible. The effectiveness of the ANOPS system for recognizing neuropathic and myopathic disorders in proximal muscles of the limbs has been described elsewhere (Sica et al, 1978).

\section{ACKNOWLEDGEMENTS}

Our thanks are due to Dr. S. J. Kopec and Dr. J. Delbeke for their invaluable help at the start of this study. Heidi Roth and Glenn Shine provided technical assistance and Norma Zimmerman kindly typed the manuscript.

\section{REFERENCES}

BALLANTYNE, J. P. and HANSEN, S. (1974). A new method for the estimation of the number of motor units in a muscle. 1. Control subjects and patients with myasthenia gravis. Journal of Neurology, Neurosurgery and Psychiatry, 37, 907-915.
BROWN, W. F. (1972). A method for estimating the number of motor units in thenar muscles and changes in motor unit counting with ageing. Journal of Neurology, Neurosurgery and Psychiatry, 35, 845-852.

BROWN, W. F. and FEASBY, T. E. (1974). Estimates of functional motor axon loss in diabetes. Journal of the Neurological Sciences, 23, 275-293.

CAMPBELL, M. J., McCOMAS, A. J. and PETITO, F. (1973). Physiological changes in ageing muscles. Journal of Neurology, Neurosurgery and Psychiatry, 36, 174-182.

EISEN, A., KARPATI, G., CARPENTER, S. and DANON, J. (1974). The motor unit profile of the rat soleus in experimental myopathy and reinnervation. Neurology (Minneapolis), 24, 874-884.

FUGLSANG-FREDERIKSEN, A., SCHEEL, U. and BUCHTHAL, F. (1976). Diagnostic yield of analysis of the pattern of electrical activity and of individual motor unit potentials in myopathy. Journal of Neurology, Neurosurgery and Psychiatry, 39, 742-750.

FUGLSANG-FREDERIKSEN, A., SCHEEL. U. and BUCHTHAL, F. (1977). Diagnostic yield of the analysis of the pattern of electrical activity and of individual motor unit potentials in neurogenic involvement. Journal of Neurology, Neurosurgery and Psychiatry, 40, 544-554.

HANSEN, $S$. and BALLANTYNE, J. P. (1977). Axonal dysfunction in the neuropathy of diabetes mellitus: a quantitative electrophysiological study. Journal of Neurology, Neurosurgery and Psychiatry, 40, 555-564.

HAYWARD, M. (1977). Automatic analysis of the electromyogram in healthy subjects of different ages. Journal of the Neurological Sciences, 33, 387-396.

HAYWARD, M. and WILLISON, R. G. (1977). Automatic analysis of the electromyogram in patients with chronic partial denervation. Journal of the Neurological Sciences, 33, 415-423.
JENNEKENS, F. G. I., TOMLINSON, B. E. and WALTON, J. N. (1972). The extensor digitorum brevis: histological and histochemical aspects. Journal of Neurology, Neurosurgery and Psychiatry, 35, 124-132.

KOPEC, J. and HAUSMANOWA. PETRUSEWICZ, 1. (1976). On-line computer application in clinical quantitative electromyography. Electromyography and Clinical Neurophysiology, 16, 49-64.

McCOMAS, A. J. (1977). Neuromuscular Function and Disorders. 364 p. London: Butterworths.

McCOMAS, A. J., FAWCETT, P. R. W., CAMPBELL, M. J. and SICA, R. E. P. (1971). Electrophysiological estimation of the number of motor units within a human muscle. Journal of Neurology, Neurosurgery and Psychiatry, 34, 121-137.

PANAYIOTOPOULOS, C. P. and SCARPALEZOS, S. (1975). Electrophysiological estimation of motor units in limb-girdle muscular dystrophy and chronic spinal muscular atrophy. Journal of the Neurological Sciences, 24, 95-107.

PEYRONNARD, J-M. and LAMARRE. Y. (1977). Electrophysiological and anatomical estimation of the number of motor units in the monkey extensor digitorum brevis muscle. Journal of Neurology, Neurosurgery and Psychiatry, 40, 756-764.

SICA, R. E. P., McCOMAS, A. J. and FERREIRA, J. C. D. (1978). Evaluation of an automatic method for analysing the electromyogram. Canadian Journal of Neurological Sciences, 5, 275-281.

SICA, R. E. P., McCOMAS, A. J., UPTON, A. R. M. and LONGMIRE, D. (1974). Estimations of motor units in small muscles of the hand. Journal of Neurology. Neurosurgery and Psychiatry, 37, 55-67.

WILLISON, R. G. (1964). Analysis of electrical activity in healthy and dystrophic muscle in man. Journal of Neurology, Neurosurgery and Psychiatry, 27, 386-394. 